\title{
Clinical and histologic evaluation of different approaches to gain keratinized tissue prior to implant placement in fully edentulous patients
}

Thoma, Daniel S ; Alshihri, AbdulMonem ; Fontolliet, Alain ; Hämmerle, Christoph H F ; Jung, Ronald E ; Benic, Goran I

\begin{abstract}
OBJECTIVES: This work aimed to investigate the effectiveness and predictability of different treatment modalities for gain of keratinized tissue (KT) in fully edentulous jaws prior to dental implant placement: apically positioned flap (APF), APF plus xenogeneic collagen matrix (XCM), and APF plus free gingival graft (FGG). MATERIALS AND METHODS: In fully edentulous patients with insufficient zones of KT at the prospective implant positions, four treatment modalities were performed in the lower jaw: APF, XCM, FGG, and an untreated control group (control). APF and XCM were applied in the first molar positions, FGG and control in the canine positions. Assessed outcomes up to 3 months post-surgery included changes in width of KT (over a 3-month period), histomorphometric analysis of harvested soft-tissue biopsies (at 3 months postoperatively), and patient-reported outcomes measures (PROMs). RESULTS: For the primary outcome, changes in KT width demonstrated an increase of $1.93 \pm 1.6 \mathrm{~mm}(\mathrm{APF})$, whereas XCM and FGG showed an increase of $4.63 \pm 1.25 \mathrm{~mm}$ and $3.64 \pm 2.01$, respectively. Histomorphometric analyses revealed a thickness of the epithelium ranging between $375 \pm 122 \mu \mathrm{m}$ (APF), $410 \pm 116 \mu \mathrm{m}$ (XCM), $336 \pm 122 \mu \mathrm{m}$ (FGG), and $413 \pm 109 \mu \mathrm{m}$ (control). All biopsies showed a regular muco-periosteal structure with a keratinized epithelium of comparable thickness in all groups. CONCLUSION: All three methods were suitable to increase the width of KT, although APF alone rendered roughly $50 \%$ less gain compared to XCM and FGG. CLINICAL RELEVANCE: The use of XCM in conjunction with an APF represents a valuable treatment option for the gain of keratinized tissue in edentulous sites.
\end{abstract}

DOI: https://doi.org/10.1007/s00784-017-2319-4

Posted at the Zurich Open Repository and Archive, University of Zurich

ZORA URL: https://doi.org/10.5167/uzh-149312

Journal Article

Accepted Version

Originally published at:

Thoma, Daniel S; Alshihri, AbdulMonem; Fontolliet, Alain; Hämmerle, Christoph H F; Jung, Ronald E; Benic, Goran I (2018). Clinical and histologic evaluation of different approaches to gain keratinized tissue prior to implant placement in fully edentulous patients. Clinical Oral Investigations, 22(5):2111-2119.

DOI: https://doi.org/10.1007/s00784-017-2319-4 
Clinical and histologic evaluation of different approaches to gain keratinized tissue prior to implant placement in fully edentulous patients

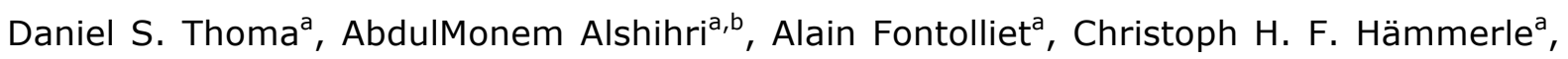
Ronald E. Jung ${ }^{a}$, Goran I. Benic ${ }^{a}$

${ }^{a}$ Clinic for Fixed and Removable Prosthodontics and Dental Material Science, University of Zurich, Switzerland

${ }^{b}$ Department of prosthodontics and biomaterials, King Saud University, Riyadh, SA

Running title: increase of keratinized tissue

Key words: collagen, matrix, augmentation, keratinized tissue, keratinized mucosa, autologous, gingival graft, transplantation, Patient-reported outcome measures

Address for correspondence: PD Dr. Daniel S. Thoma

Clinic of Fixed and Removable Prosthodontics and Dental Material Science

Dental School, University of Zurich

Plattenstrasse 11, CH-8032 Zurich, Switzerland

Phone: +41446343251

Fax: +41446344305

e-mail:daniel.thoma@zzm.uzh.ch 
ABSTRACT

Objectives: to investigate the effectiveness and predictability of different treatment modalities for gain of keratinized tissue (KT) in fully edentulous jaws prior to dental implant placement: apically positioned flap (APF), APF plus xenogeneic collagen matrix $(X C M)$, APF plus free gingival graft (FGG).

Materials \& Methods: In fully edentulous patients with insufficient zones of KT at the prospective implant positions, four treatment modalities were performed in the lower jaw: APF, XCM, FGG and an untreated control group (control). APF and XCM were applied in the first molar positions, FGG and control in the canine positions. Assessed outcomes up to 3 months post-surgery included: changes in width of KT (over a 3-month period), histomorphometric analysis of harvested soft tissues biopsies (at 3 months postoperatively) and patient-reported outcomes measures (PROMs).

Results: For the primary outcome, changes in $\mathrm{KT}$ width demonstrated an increase of $1.93 \mathrm{~mm} \pm 1.6 \mathrm{~mm}$ (APF), whereas XCM and FGG showed an increase of $4.63 \mathrm{~mm} \pm 1.25$ $\mathrm{mm}$ and $3.64 \pm 2.01$, respectively. Histomorphometric analyses revealed a thickness of the epithelium ranging between $375 \pm 122$ um (APF), 410 $\pm 116 u m$ (XCM), 336 \pm 122 um (FGG) and 413 \pm 109 um (Control). All biopsies showed a regular muco-periosteal structure with a keratinized epithelium of comparable thickness in all groups.

Conclusion: All three methods were suitable to increase the width of KT, although APF alone rendered roughly $50 \%$ less gain compared to XCM and FGG.

Clinical Relevance: The use of XCM in conjunction with an APF represents a valuable treatment option for the gain of keratinized tissue in edentulous sites. 


\section{INTRODUCTION}

Controversial results are reported with respect to the question whether or not

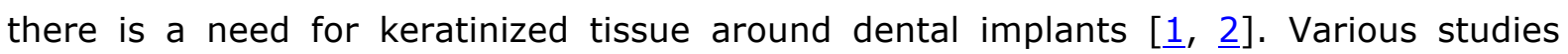
suggested associations between an adequate width of keratinized tissue, higher survival rates of dental implants, the health of the peri-implant tissue, and an improved esthetic outcome [3-5]. More recent studies demonstrated that implants with a reduced width of peri-implant keratinized tissue were more prone to plaque accumulation and bleeding as well as soft tissue recessions [6-9]. In a randomized clinical study, free gingival grafts (FGGs) significantly increased the width of keratinized mucosa around dental implants. Moreover, implant sites augmented with FGGs showed a significantly reduced mucosal inflammation and less alveolar bone loss [1이. In order to facilitate patients' oral hygiene and to maintain the keratinized mucosa level, techniques to increase the peri-implant keratinized tissue have to be considered. Traditionally, grafting procedures are performed using autogenous soft tissue transplants [11-13]. However, surgical difficulties, lack of color match, and an increased patient morbidity represent major disadvantages when using autogenous transplants [14-18]. In order to overcome these issues encountered with autogenous grafting, various techniques and biomaterials of allogenic and xenogeneic origin were introduced and evaluated in clinical studies to increase the width of keratinized tissue [19-24]. Collagen devices from xenogeneic origin have been successfully used in dentistry as barrier membranes [25-27], as socket seal [28-30] and to gain keratinized tissue $[\underline{19}, \underline{21-23}, \underline{31}, \underline{32}]$. Even though, results from clinical trials demonstrated that a collagen matrix (XCM) in combination with an apically positioned flap (APF) was effective and predictable for attaining a band of keratinized tissue $[\underline{21}, \underline{23}, \underline{32}, \underline{33}]$, a clinical benefit compared to the APF alone has not been shown so far.

The aim of the present pilot study was, therefore, to evaluate four treatment modalities, an apically positioned flap (APF), APF plus XCM, APF plus FGG and an untreated control 
group, in prospective implant positions and to report histologic outcomes three months following the surgical interventions. 


\section{MATERIALS AND Methods}

\section{Study design}

The present study was designed as a split-mouth pilot case series to evaluate three procedures for gain of keratinized tissue and to histologically describe the tissues three months after the surgical interventions. The local ethics committee approved the study protocol and procedures (KEK-Nr. 2011-0124/5). Patients meeting the following inclusion criteria were consecutively recruited and enrolled at the Clinic of Fixed and Removable Prosthodontics and Dental Material Science, University of Zürich, Switzerland, between 2011-2012:

- Signed informed consent

- The patient (male or female) must be 18 years or older

- The patient is able to comply with the study-related procedures such as exercising good oral hygiene and attending all follow-up procedures

- The patient is able to fully understand the nature of the proposed surgery and is able to provide a signed informed consent.

- Fully edentulous patients in need of implant therapy in the mandible and ability to place dental implants in the two canine and the two first molar positions

- A reduced width of keratinized tissue $(<2 \mathrm{~mm})$, measured from the center of the four prospective mandibular implant positions (canines and first molars) to the buccal mucogingival junction

- Well-fitted, new maxillary and mandibular prostheses

- Generally healthy

- Commitment to maintain good oral hygiene

- No systemic disease that could affect wound healing and prevent implant placement

Exclusion criteria for all subjects included:

- Patient is a heavy smoker ( $>10$ cigarettes per day)

- Patient is an insulin dependent diabetic

- General contraindications for dental and/or surgical treatment are present.

- The patient has a history of malignancy, radiotherapy, or chemotherapy for malignancy within the past five. 
- The patient is pregnant or nursing

- The patient is taking medications or having treatments, which have an effect on mucosal healing in general (e.g. steroids, large doses of anti-inflammatory drugs).

- The patient has a disease, which affects connective tissue metabolism (e.g. collagenases).

- The patient is allergic to collagen.

- Patients having participated in a clinical trial within the last six months.

Patients not meeting all inclusion criteria were excluded from the study. Upon enrollment, alginate impressions of the mandible were obtained and stents for measurements were digitally designed and fabricated with a 3D printer (Figure 1). The stent was designed in such a way that it allowed measuring the width of keratinized tissue from the center of the prospective implant positions to the buccal mucogingival junction.

\section{Surgical intervention}

At the day of surgery, patients rinsed with $0.2 \%$ of chlorhexidine solution and were given medication for pain relief (Mefenamic acid, 500mg). Subsequently, photographs of the four sites were taken, and the width of keratinized tissue was measured on the buccal side of the four prospective implant positions using a caliper and the prepared stent. Following local anesthesia, four treatment modalities were then randomly applied to the left and right side of the mandible:

Molar positions:

- Apically positioned flap (APF)

- APF plus collagen matrix (XCM) (Mucograft ${ }^{\circledR}$ Geistlich Pharma AG, Wolhusen, Switzerland)

Canine positions:

- APF plus autogenous free gingival graft (FGG) 
- No surgical intervention (control)

In group APF (Figure 2), a split-flap was prepared leaving $1 \mathrm{~mm}$ of keratinized tissue (KT) at the coronal border of the APF and sutured apically using non-resorbable sutures (Dafilons 5-0, B. Braun Melsungen AG, Melsungen, Germany). The periosteum was exposed with a height of $7 \mathrm{~mm}$ and a width of $10 \mathrm{~mm}$ and left for spontaneous healing. At XCM sites (Figure 2), the same procedure (split-flap with $1 \mathrm{~mm}$ of $\mathrm{KT}$ ) was performed. Subsequently, the XCM was shaped to a final dimension of $5 \times 10 \mathrm{~mm}$ and sutured coronally. A gap of $2 \mathrm{~mm}$ was left for spontaneous healing between the apical border of the XCM and the coronal border of the split-flap. One or two cross-section sutures were placed on top of the XCM to stabilize the matrix on the wound bed. In the FGG group (Figure 2), a similar APF was performed (including $1 \mathrm{~mm}$ of KT). A FGG with a thickness of $1.5 \mathrm{~mm}$ and a dimension of $5 \times 10 \mathrm{~mm}$ was harvested from the palate. The FGG was sutured coronally and stabilized with one or two cross-section sutures. Similar to XCM sites, $2 \mathrm{~mm}$ of periosteum were left for healing by secondary intention. One site was left as a negative control group (no further intervention) (Figure 2).

Patients were given medications for pain relief (Mefenamic acid, 500mg every 8 hours), as well as a disinfectant solution (Chlorhexidine digluconate, $0.2 \%$ solution for rinsing every 8 hours for a period of 7 days). No adaptations were made to the mandibular prostheses and patients were allowed to wear them during the entire study period. At day 7 post-surgery, all patients were recalled for suture removal, clinical measurements and clinical photographs.

\section{Outcome measures}

\section{Width of keratinized tissue}

The width of keratinized tissue at the four sites was recorded to the nearest $0.1 \mathrm{~mm}$ at baseline (prior to surgery), after surgery, at 7 days, 30 days, and at 90 days using a caliper and 3D-printed stent (Bio-compatible PolyJet photopolymer (MED610), 
Stratasys, MN, USA) to standardize the measurements for reference and accurate reproducibility (Figure 1). The measurements were performed 5 times at a $1 \mathrm{~mm}$ distance and per site. One examiner not involved in the clinical procedure performed all the measurements. Intra-examiner reproducibility was assured by pre-operative calibration and training program on 3D-printed stent insertion, stabilization and consistent data collection.

\section{Patient-reported outcome measures}

Patient-reported outcome measures (PROMs) were evaluated post-surgically. For that purpose, a questionnaire was handed out and explained to the patients. Assessed parameters included bleeding, swelling and pain. Patients recorded their binary answers (yes/no) for bleeding (immediately post-surgery and on the following day) and for swelling (post-surgery to 7 days). Patients' pain experience was evaluated using a visual analogue scale (VAS) ranging from $0-10$, with 0 representing the absence of pain, 1-3 for minimal pain, 4-6 for moderate and 7-10 for severe pain.

\section{Histologic processing and analysis}

At 90 days following soft tissue augmentation, clinical measurements and photographs were obtained (Figure 2). In the four prospective implant positions, soft tissue biopsies were obtained using a biopsy drill (diameter $1.8 \mathrm{~mm}$; depth $5 \mathrm{~mm}$ ). Specimens were placed in $10 \%$ neutral-buffered formalin solution for fixation. Subsequently, implant placement was performed according to the manufacturer's recommendation (data not reported here). After fixation, each sample was processed and dehydrated in alcohol solutions of increasing concentration, cleared in isoparaffin $\mathrm{H}$ and embedded in paraffin. Embedded samples were cut at $5 \mu \mathrm{m}$ using a microtome (MICROM ${ }^{\circledR}$, France), sections were prepared and stained with H\&E. 
All histological sections were evaluated using a Nikon microscope (ECLIPSE E600, Nikon, Egg, Switzerland) for qualitative and semi-quantitative histological analysis. For histomorphometric analysis, the digitized histological images were analyzed using an image-processing program (Image J, NIH, Bethesda, USA), to assess the thickness of keratinized epithelium (Figure 3).

\section{Statistical analysis}

Statistical analyses were performed descriptively to compare the different treatment modalities at 30 and 90 days and for changes over time. Current statistics (mean, standard deviation, median and IQR) were used to describe the quantitative parameters of keratinized tissue width and microscopic thickness of the epithelium (day 90). Due to the small sample size, no further statistical tests were performed.

\section{Results}

A total of 9 patients (36 sites) in fully edentulous patients with an age range between 46-88 years (mean 66.3 years) were included in the study and underwent soft tissue augmentation surgeries. All patients received 4 treatment modalities, healing was generally uneventful and no local infection was observed at suture removal. Patientrelated outcomes at day 7 postoperatively were collected in form of a questionnaire. In $33 \%$ of the sites (irrespective of the treatment modality), moderate to severe pain was reported. Absence of pain was reported in $13.9 \%$ of the sites only (Table 1 ).

\section{Width of keratinized tissue}

All data are presented in Table 2 . Immediately post surgery, the gain in KT obtained due to the surgical interventions ranged between $3.69 \mathrm{~mm} \pm 1.62 \mathrm{~mm}$ (APF), $4.31 \mathrm{~mm} \pm$ $0.76 \mathrm{~mm}(\mathrm{XCM}), 4.44 \mathrm{~mm} \pm 1.44 \mathrm{~mm}(\mathrm{FGG})$ and $0.0 \mathrm{~mm} \pm 0.0 \mathrm{~mm}$ (control). 
Between preoperative and 90 days, the gain in width of KT up to 90 days was $1.93 \mathrm{~mm}$ $\pm 1.6 \mathrm{~mm}$ for $A P F, 4.63 \mathrm{~mm} \pm 1.25 \mathrm{~mm}$ for $X C M, 3.64 \pm 2.01 \mathrm{~mm}$ for FGG and $0.13 \mathrm{~mm} \pm$ $0.31 \mathrm{~mm}$ for control.

From postoperative to day 90 , the width of KT decreased by $35.5 \%$ for APF, increased by $6.8 \%$ for XCM, and decreased by $16.8 \%$ for FGG and increased by $3.4 \%$ for control sites.

\section{Descriptive histology}

Eight out of 9 patients agreed to take biopsies at 90 days post surgery. In all 8 patients, 4 biopsies were collected at the prospective implant positions. A total of 24 biopsies could be processed and analyzed. This included 5 APF, 5 XCM sites, 7 FGG sites and 7 control sites. Microscopically, the harvested soft tissues appeared to be healthy. In the most coronal part of the biopsy, the oral epithelium had a regular appearance with all four components, a keratinized stratum corneum with a keratin layer, a stratum granulosum, a stratum spinosum and a stratum basale. Rete pegs were present, but had an irregular appearance in most cases. The subepithelial connective tissue appeared to have a loose structure with relatively thin bundles of collagen fibers in most biopsies, whereas in some samples, thick bundles of collagen fibers were surrounded by an increased number of blood vessels. Few inflammatory cells (macrophages, lymphocytes, granulocytes) were present in the most coronal portion of the connective tissue compartment. In APF and XCM sites, the structure and shape of the epithelium underlying connective tissue appeared to be quite consistent, while in control and FGG sites, more inconsistencies and irregularities of shape and form were visible. Some remnants of the collagen matrices were observed in XCM sites in the most coronal part of the connective tissue.

\section{Histomorphometric outcomes}


The histomorphometric analysis revealed a thickness of the epithelium ranging between $375 \pm 122$ um (APF), 410 \pm 116 um (XCM), 336 \pm 122 um (FGG) and $413 \pm 109$ um (control) at 90 days post surgery (Figure 4A-D). 


\section{Discussion}

The present study evaluating three methods to increase the width of keratinized tissue in fully edentulous mandibles revealed that: i) in posterior sites, XCM was more effective in terms of gain of KT than APF alone, ii) in anterior sites, FGG resulted in a gain similar to XCM sites in the posterior region, iii) postoperative bleeding occurred frequently and irrespective of the treatment modality, iv) absence of pain was more frequently observed for APF and XCM sites than for FGG sites, v) similar histologic outcomes in all groups at 90 days post-surgery.

To date, there is no data available assessing the use of collagen matrix in fully edentulous jaws prior to implant placement, aiming at gain of keratinized tissue. Moreover, the clinical and patient benefit of an XCM compared to an apically positioned flap alone is unknown. The APF procedure, without incorporating any additional grafting material (XCM, FGG) covering the wound bed, resulted in the least gain of keratinized tissue. Few studies showed similar outcomes when using an APF to regenerate KT in partially edentulous patients $[\underline{34}, \underline{35}]$. In a case report of 3 patients, an average of 1.5 $\mathrm{mm}$ of KT was gained 3-4 weeks post-APF procedure [35]. Another clinical study showed an increase of $2 \mathrm{~mm}$, after 3 months of APF procedure, that decreased to 1.15 $\mathrm{mm}$ at the 12-month follow up [34]. Bearing in mind that a minimum of $2 \mathrm{~mm}$ width of KT is generally considered to be sufficient and that it is however unknown if a wider band of KT is clinically more advantageous $[\underline{8}, \underline{9}, \underline{36}]$, the obtained gain through an APF might still have its clinical indication.

Collagen matrices were applied for various clinical indications, including gingival recession coverage and to increase the width and thickness of gingival/ peri-implant keratinized mucosa $[\underline{12}, \underline{19-22}, \underline{37}]$. The present XCM has a 3-dimensional structure to support the tissue growth, while allowing the cellular adhesion and infiltration into its interconnected porosity [38]. It is made of a collagenous framework that is biocompatible and biodegradable to be replaced by native tissue $[20,38-40]$. The 
present clinical findings demonstrated an increase in KT width by more than double compared to APF alone. It might in part be explained by the previously mentioned favorable biologic and chemical properties.

Traditionally, autogenous free gingival grafts were considered to be the gold standard for its high success and predictability, as well as the lack for comparable alternatives $[11,12,41-43]$. In the present study, XCM regenerated a width of keratinized tissue that was comparable to the FGG sites at 3 months. These findings are in line with previous clinical studies $[\underline{19-21}, \underline{23}, \underline{32}, \underline{43}]$. Since the sites (FGG at canine positions; XCM at molar positions) were not randomized and differed between the area/treatment modalities and based on the pilot character of the study, the results were only compared descriptively without applying further statistical tests. This pilot study could however be of value for the power calculation and design of future studies.

It is accepted to expect some degree of wound contraction and augmentation shrinkage irrespective of the procedure and materials used. Postsurgical soft tissue changes in width and overall shrinkage are a valuable indicative of technique predictability. Literature has shown a wide variation in the amount of shrinkage associated with similar or different augmentation procedures [12]. The present findings showed shrinkage rates of $35.5 \%$ for APF and of $16.8 \%$ for FGG sites, 3 months postoperatively. In contrast, XCM sites revealed an increase of $7 \%$ relative to the postoperative width of KT. Variations in soft tissue changes could be influenced by a number of factors: the surgical technique (APF vs. APF/FGG vs. APF/XCM), the augmentation site (anterior vs. posterior, periodontal vs. peri-implant), type (XCM, FGG), the characteristics of the grafting material (thickness and prevascularity) and the amount of bone atrophy in the surgical area that could sustain unfavorable muscle attachment [44]. APF, XCM and FGG were reported to exhibit the majority of shrinkage within the first 3 months post surgery $[23,33,34,43]$. Published data indicated, for XCM and FFG, a maximal shrinkage of $67 \%$ and $60 \%$, respectively, one month postoperatively [23], a shrinkage of $20 \%$ at 2 months (XCM) [33] and a shrinkage of $34 \%(\mathrm{XCM})$ and $28.6 \%(\mathrm{FGG})$ at 3 months [21] . 
All these shrinkage rates are higher than the ones observed in the present study. One possible explanation includes that all patients were fully edentulous and wearing their prostheses as opposed to the above-mentioned studies including tooth and implant sites in partially edentulous patients. The prostheses in the present study might have served as an artificial wound dressing by keeping a continuous pressure on the wound bed and by stabilization the augmented area. Another important factor is that most of clinical studies, including ours, presented relatively short-term findings. Although long-term studies are limited, a 5-year clinical study showed continuous but minimal rates of dimensional changes after the first 3 months of the treatment. The XCM-treated sites showed more significant reduction in KT compared to FGG at 3-, 4- and 5-year follow up visits. Yet, KT maintained an adequate and supportive peri-implant keratinized tissue in both groups [21].

Histologically, the biopsies showed a similar keratinization of multilayer epithelial cells, as well as a normal maturation of connective tissue structures. These histologic findings have been consistently described in previous studies assessing biopsies taken following augmentation with XCM and FGG $[\underline{19}, \underline{20}, \underline{43}]$. The histomorphometric analysis also revealed XCM-site biopsies to have a slightly thicker epithelial layer (410 $116 \mathrm{um}$ )

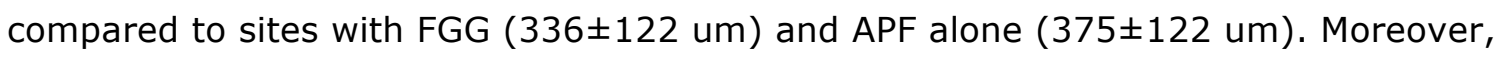
the data were comparable to sites without surgical intervention (control sites: $413 \pm 109$ um). These findings demonstrate that within a 3-month period, irrespective of the treatment modality, stable soft tissue conditions can be expected. This is in line with observations from previous in vivo studies comparing collagen matrices and sites healing spontaneously that demonstrated no differences at the respective study endpoints between 1 and 6 months $[\underline{45}, \underline{46}]$.

Patients' perception on dental care is becoming a vital tool and central outcome in clinical studies. In the present study, each patient received 3 surgical interventions within one appointment. Despite the augmented effect of different within-patient interventions, bleeding, swelling and pain were within 'well-tolerated' range. In general, 
patients had the perception of "mild-moderate" within the first week postoperatively. Moreover, patients reported absence of pain more frequently with APF and XCM compared to FGG. Postoperative bleeding and swelling occurred frequently, and irrespective of the treatment modality. These data are further limited and need to be interpreted with caution due to the lack of an overall randomization and a relatively low number of patients. It is also more indicative for future studies to investigate and compare similar anatomical sites for the intervention of interest, over a longer period of follow up.

\section{CONCLUSIONS}

All three methods were suitable to increase the width of $\mathbf{K T}$, although APF alone rendered roughly $50 \%$ less gain compared to XCM and FGG. From a histologic point of view, all three-treatment modalities led to matured and stable soft tissues similar to native gingival tissue three months following the surgical interventions.

\section{Compliance with Ethical Standards}

Conflict of Interest: Daniel S. Thoma declares that he has no conflict of interest. AbdulMonem Alshihri declares that he has no conflict of interest. Alain Fontolliet declares that he has no conflict of interest. Christoph H. F. Hämmerle declares that he has no conflict of interest. Ronald E. Jung declares that he has no conflict of interest. Goran I. Benic declares that he has no conflict of interest.

Funding: The present study was supported by the Clinic of Fixed and Removable Prosthodontics and Dental Material Science, University of Zurich and by a research grant of Geistlich Pharma AG, Wolhusen, Switzerland.

Ethical approval: All procedures performed in studies involving human participants were in accordance with the ethical standards of the institutional and/or national research 
committee and with the 1964 Helsinki declaration and its later amendments or comparable ethical standards.

Informed consent: Informed consent was obtained from all individual participants included in the study. 


\section{FIGURE LEGENDS}

Figure 1

3D printed surgical stent for reproducible clinical measurements, inserted on an edentulous mandible. Treatment modalities: lower left: FGG; lower right: control; upper left: APF; upper right: XCM. APF = apically positioned flap; XCM = xenogeneic collagen matrix; FGG = free gingival graft.

Figure 2

Clinical situation at 90 days. Treatment modalities: lower left: FGG; lower right: control; upper left: XCM; upper right: APF. APF = apically positioned flap; XCM = xenogeneic collagen matrix; FGG = free gingival graft.

Figure 3

Histologic section (H\&E staining), showing the epithelial measurements (magnification 50 $X)$.

Figure 4

A-D: Histologic sections (H\&E staining) 90 days after surgery (original magnification x50). A: apically positioned flap (APF) site. B: XCM (xenogeneic collagen matrix) site. C: FGG (free gingival graft) site. D: control site.

Table 1

7-day postoperative patient-related outcome measures. APF = apically positioned flap; $\mathrm{XCM}=$ xenogeneic collagen matrix; FGG $=$ free gingival graft.

Table 2 
Width of keratinized tissue ( $\Delta$ mean $\mathrm{mm}$, standard deviation (SD), median, quartile 1 and quartile 3$).$ APF = apically positioned flap; XCM = xenogeneic collagen matrix; FGG = free gingival graft; $\mathrm{SD}=$ standard deviation; $\mathrm{Q} 1$ = quartile $1 ; \mathrm{Q} 3$ = quartile 3 . 


\section{References:}

[1] Lin GH, Chan HL and Wang HL (2013) The significance of keratinized mucosa on implant health: a systematic review. J Periodontol 84:1755-67. doi: 10.1902/jop.2013.120688

[2] Wennstrom JL and Derks J (2012) Is there a need for keratinized mucosa around implants to maintain health and tissue stability? Clin Oral Implants Res 23 Suppl 6:13646. doi: $10.1111 / \mathrm{j} .1600-0501.2012 .02540 . x$

[3] Adell R, Lekholm U, Rockler B, Branemark PI, Lindhe J, Eriksson B and Sbordone L (1986) Marginal tissue reactions at osseointegrated titanium fixtures (I). A 3-year longitudinal prospective study. Int J Oral Maxillofac Surg 15:39-52.

[4] Artzi Z, Tal H, Moses O and Kozlovsky A (1993) Mucosal considerations for osseointegrated implants. J Prosthet Dent 70:427-32.

[5] Langer B (1996) The regeneration of soft tissue and bone around implants with and without membranes. Compend Contin Educ Dent 17:268-70, 272 passim; quiz 280.

[6] Romanos G, Grizas E and Nentwig GH (2015) Association of Keratinized Mucosa and Periimplant Soft Tissue Stability Around Implants With Platform Switching. Implant Dent 24:422-6. doi: 10.1097/ID.0000000000000274

[7] Souza AB, Tormena M, Matarazzo F and Araujo MG (2016) The influence of periimplant keratinized mucosa on brushing discomfort and peri-implant tissue health. Clin Oral Implants Res 27:650-5. doi: 10.1111/clr.12703

[8] Schrott AR, Jimenez M, Hwang JW, Fiorellini J and Weber HP (2009) Five-year evaluation of the influence of keratinized mucosa on peri-implant soft-tissue health and stability around implants supporting full-arch mandibular fixed prostheses. Clin Oral Implants Res 20:1170-7. doi: 10.1111/j.1600-0501.2009.01795.x

[9] Ueno D, Nagano T, Watanabe T, Shirakawa S, Yashima A and Gomi K (2016) Effect of the Keratinized Mucosa Width on the Health Status of Periimplant and Contralateral Periodontal Tissues: A Cross-sectional Study. Implant Dent 25:796-801. doi: 10.1097/ID.0000000000000483 
[10] Oh SL, Masri RM, Williams DA, Ji C and Romberg E (2017) Free gingival grafts for implants exhibiting lack of keratinized mucosa: a prospective controlled randomized clinical study. J Clin Periodontol 44:195-203. doi: 10.1111/jcpe.12660

[11] Bassetti RG, Stahli A, Bassetti MA and Sculean A (2017) Soft tissue augmentation around osseointegrated and uncovered dental implants: a systematic review. Clin Oral Investig 21:53-70. doi: 10.1007/s00784-016-2007-9

[12] Thoma DS, Buranawat B, Hammerle CH, Held U and Jung RE (2014) Efficacy of soft tissue augmentation around dental implants and in partially edentulous areas: a systematic review. J Clin Periodontol 41 Suppl 15:S77-91. doi: 10.1111/jcpe.12220

[13] Seibert JS (1983) Reconstruction of deformed, partially edentulous ridges, using full thickness onlay grafts. Part I. Technique and wound healing. Compend Contin Educ Dent 4:437-53.

[14] McGuire MK and Nunn ME (2005) Evaluation of the safety and efficacy of periodontal applications of a living tissue-engineered human fibroblast-derived dermal substitute. I. Comparison to the gingival autograft: a randomized controlled pilot study. J Periodontol 76:867-80.

[15] McGuire MK, Scheyer ET, Nunn ME and Lavin PT (2008) A pilot study to evaluate a tissue-engineered bilayered cell therapy as an alternative to tissue from the palate. J Periodontol 79:1847-56.

[16] Soileau KM and Brannon RB (2006) A histologic evaluation of various stages of palatal healing following subepithelial connective tissue grafting procedures: a comparison of eight cases. J Periodontol 77:1267-73.

[17] Farnoush A (1978) Techniques for the protection and coverage of the donor sites in free soft tissue grafts. J Periodontol 49:403-5.

[18] Griffin TJ, Cheung WS, Zavras AI and Damoulis PD (2006) Postoperative complications following gingival augmentation procedures. J Periodontol 77:2070-9.

[19] McGuire MK and Scheyer ET (2014) Randomized, controlled clinical trial to evaluate a xenogeneic collagen matrix as an alternative to free gingival grafting for oral soft tissue augmentation. J Periodontol 85:1333-41. doi: 10.1902/jop.2014.130692 
[20] Nevins M, Nevins ML, Kim SW, Schupbach P and Kim DM (2011) The use of mucograft collagen matrix to augment the zone of keratinized tissue around teeth: a pilot study. Int J Periodontics Restorative Dent 31:367-73.

[21] Schmitt CM, Moest T, Lutz R, Wehrhan F, Neukam FW and Schlegel KA (2016) Long-term outcomes after vestibuloplasty with a porcine collagen matrix (Mucograft(R)) versus the free gingival graft: a comparative prospective clinical trial. Clin Oral Implants Res 27:e125-e133. doi: 10.1111/clr.12575

[22] Jepsen K, Jepsen S, Zucchelli G, Stefanini M, de Sanctis M, Baldini N, Greven B, Heinz B, Wennstrom J, Cassel B, Vignoletti F and Sanz M (2013) Treatment of gingival recession defects with a coronally advanced flap and a xenogeneic collagen matrix: a multicenter randomized clinical trial. J Clin Periodontol 40:82-9. doi: 10.1111/jcpe.12019 [23] Sanz M, Lorenzo R, Aranda J], Martin C and Orsini M (2009) Clinical evaluation of a new collagen matrix (Mucograft prototype) to enhance the width of keratinized tissue in patients with fixed prosthetic restorations: a randomized prospective clinical trial. J Clin Periodontol 36:868-76. doi: 10.1111/j.1600-051X.2009.01460.x

[24] Thoma DS, Zeltner M, Hilbe M, Hammerle CH, Husler J and Jung RE (2016) Randomized controlled clinical study evaluating effectiveness and safety of a volumestable collagen matrix compared to autogenous connective tissue grafts for soft tissue augmentation at implant sites. J Clin Periodontol 43:874-85. doi: 10.1111/jcpe.12588

[25] Sam G and Pillai BR (2014) Evolution of Barrier Membranes in Periodontal Regeneration-"Are the third Generation Membranes really here?". J Clin Diagn Res 8:ZE14-7. doi: $10.7860 / J C D R / 2014 / 9957.5272$

[26] Sheikh Z, Qureshi J, Alshahrani AM, Nassar H, Ikeda Y, Glogauer M and Ganss B (2017) Collagen based barrier membranes for periodontal guided bone regeneration applications. Odontology / the Society of the Nippon Dental University 105:1-12. doi: $10.1007 / \mathrm{s} 10266-016-0267-0$

[27] Vignoletti F, Nunez J and Sanz M (2014) Soft tissue wound healing at teeth, dental implants and the edentulous ridge when using barrier membranes, growth and 
differentiation factors and soft tissue substitutes. J Clin Periodontol 41 Suppl 15:S23-35. doi: $10.1111 /$ jcpe.12191

[28] Cortell-Ballester I, Figueiredo R, Valmaseda-Castellon E and Gay-Escoda C (2015) Effects of Collagen Resorbable Membrane Placement After the Surgical Extraction of Impacted Lower Third Molars. J Oral Maxillofac Surg 73:1457-64. doi: $10.1016 /$ j.joms.2015.02.015

[29] Meloni SM, Tallarico M, Lolli FM, Deledda A, Pisano M and Jovanovic SA (2015) Postextraction socket preservation using epithelial connective tissue graft vs porcine collagen matrix. 1-year results of a randomised controlled trial. Eur J Oral Implantol $8: 39-48$.

[30] Perelman-Karmon M, Kozlovsky A, Liloy R and Artzi Z (2012) Socket site preservation using bovine bone mineral with and without a bioresorbable collagen membrane. Int J Periodontics Restorative Dent 32:459-65.

[31] Vignoletti F, Nunez J, Discepoli N, De Sanctis F, Caffesse R, Munoz F, Lopez M and Sanz M (2011) Clinical and histological healing of a new collagen matrix in combination with the coronally advanced flap for the treatment of Miller class-I recession defects: an experimental study in the minipig. J Clin Periodontol 38:847-55. doi: 10.1111/j.1600051X.2011.01767.x

[32] Lorenzo R, Garcia V, Orsini M, Martin C and Sanz M (2012) Clinical efficacy of a xenogeneic collagen matrix in augmenting keratinized mucosa around implants: a randomized controlled prospective clinical trial. Clin Oral Implants Res 23:316-24. doi: $10.1111 / \mathrm{j} .1600-0501.2011 .02260 . x$

[33] Herford AS, Akin L, Cicciu M, Maiorana C and Boyne PJ (2010) Use of a porcine collagen matrix as an alternative to autogenous tissue for grafting oral soft tissue defects. J Oral Maxillofac Surg 68:1463-70. doi: 10.1016/j.joms.2010.02.054

[34] Basegmez C, Ersanli S, Demirel K, Bolukbasi N and Yalcin S (2012) The comparison of two techniques to increase the amount of peri-implant attached mucosa: free gingival grafts versus vestibuloplasty. One-year results from a randomised controlled trial. Eur J Oral Implantol 5:139-45. 
[35] Lee KH, Kim BO and Jang HS (2010) Clinical evaluation of a collagen matrix to enhance the width of keratinized gingiva around dental implants. J Periodontal Implant Sci 40:96-101. doi: 10.5051/jpis.2010.40.2.96

[36] Chiu YW, Lee SY, Lin YC and Lai YL (2015) Significance of the width of keratinized mucosa on peri-implant health. J Chin Med Assoc 78:389-94. doi: 10.1016/j.jcma.2015.05.001

[37] Aroca S, Molnar B, Windisch P, Gera I, Salvi GE, Nikolidakis D and Sculean A (2013) Treatment of multiple adjacent Miller class I and II gingival recessions with a Modified Coronally Advanced Tunnel (MCAT) technique and a collagen matrix or palatal connective tissue graft: a randomized, controlled clinical trial. J Clin Periodontol 40:713-20. doi: $10.1111 /$ jcpe. 12112

[38] Atieh MA, Alsabeeha N, Tawse-Smith A and Payne AG (2016) Xenogeneic collagen matrix for periodontal plastic surgery procedures: a systematic review and metaanalysis. J Periodontal Res 51:438-52. doi: 10.1111/jre.12333

[39] Thoma DS, Sancho-Puchades M, Ettlin DA, Hammerle CH and Jung RE (2012) Impact of a collagen matrix on early healing, aesthetics and patient morbidity in oral mucosal wounds - a randomized study in humans. J Clin Periodontol 39:157-65. doi: 10.1111/j.1600-051X.2011.01823.x

[40] Willershausen I, Barbeck M, Boehm N, Sader R, Willershausen B, Kirkpatrick C] and Ghanaati S (2014) Non-cross-linked collagen type I/III materials enhance cell proliferation: in vitro and in vivo evidence. J Appl Oral Sci 22:29-37. doi: 10.1590/1678775720130316

[41] Evian CI, al-Maseeh J and Symeonides E (2003) Soft tissue augmentation for implant dentistry. Compend Contin Educ Dent 24:195-8, 200-2, 204-6; quiz 208.

[42] Marquez IC (2004) The role of keratinized tissue and attached gingiva in maintaining periodontal/peri-implant health. Gen Dent 52:74-8; quiz 79.

[43] Schmitt CM, Tudor C, Kiener K, Wehrhan F, Schmitt J, Eitner S, Agaimy A and Schlegel KA (2013) Vestibuloplasty: porcine collagen matrix versus free gingival graft: a clinical and histologic study. J Periodontol 84:914-23. doi: 10.1902/jop.2012.120084 
[44] Eufinger H, Gellrich NC, Sandmann D and Dieckmann J (1997) Descriptive and metric classification of jaw atrophy. An evaluation of 104 mandibles and 96 maxillae of dried skulls. Int J Oral Maxillofac Surg 26:23-8.

[45] Jung RE, Hurzeler MB, Thoma DS, Khraisat A and Hammerle CH (2011) Local tolerance and efficiency of two prototype collagen matrices to increase the width of keratinized tissue. J Clin Periodontol 38:173-9. doi: 10.1111/j.1600-051X.2010.01640.x [46] Thoma DS, Hilbe M, Bienz SP, Sancho-Puchades M, Hammerle CH and Jung RE (2016) Palatal wound healing using a xenogeneic collagen matrix - histological outcomes of a randomized controlled clinical trial. J Clin Periodontol 43:1124-1131. doi: $10.1111 /$ jcpe. 12624 


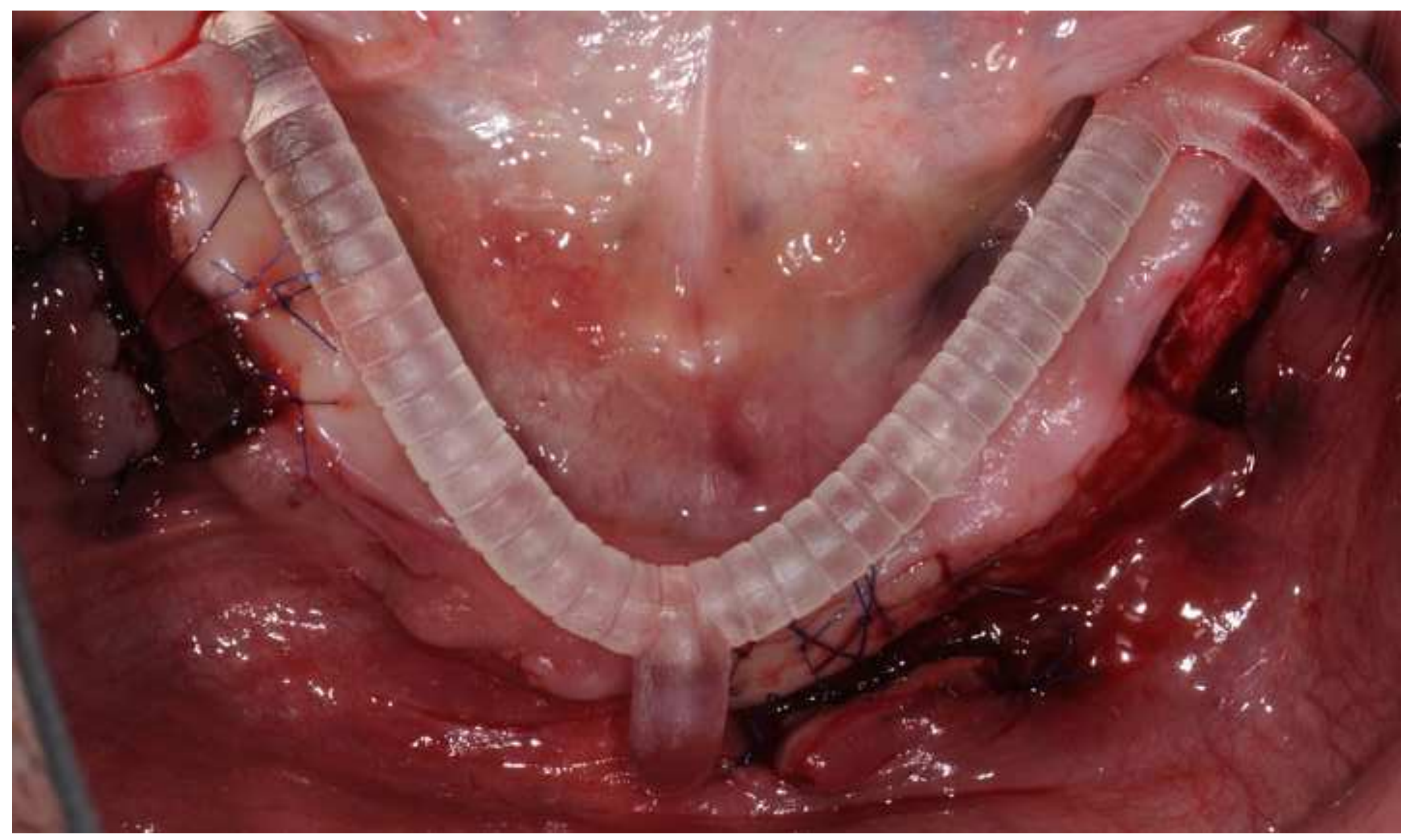

Figure 1 


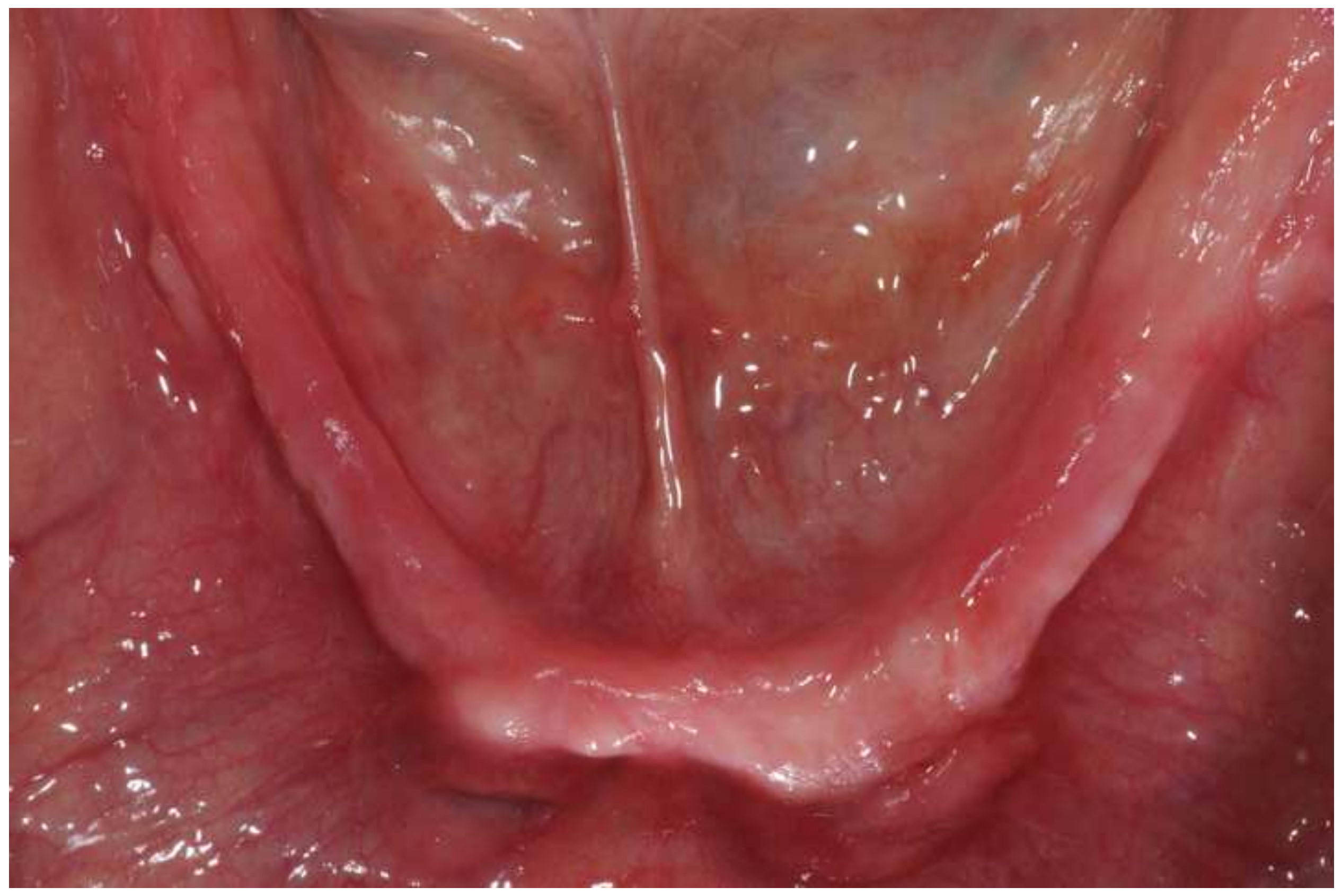




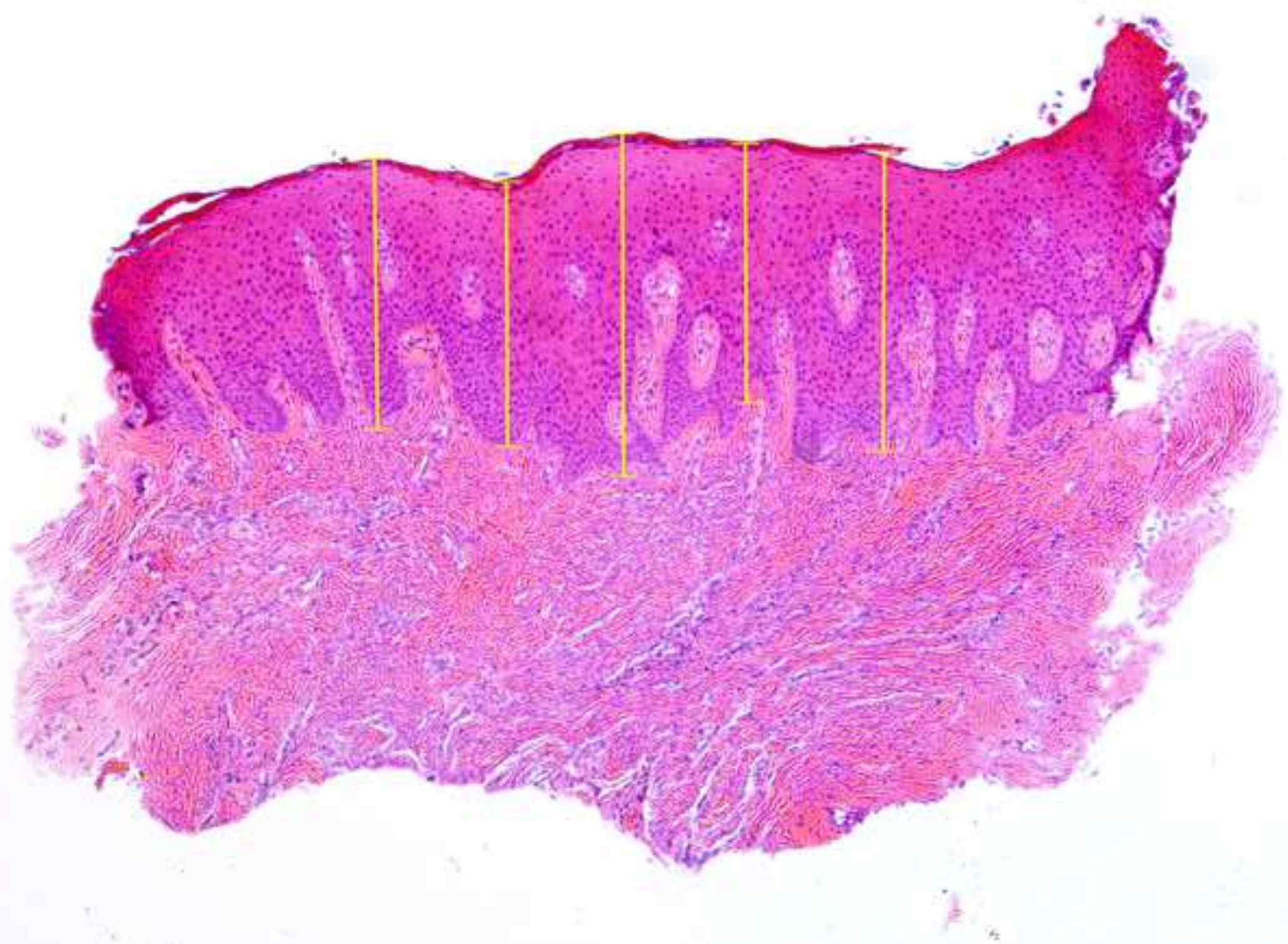

Figure 3 


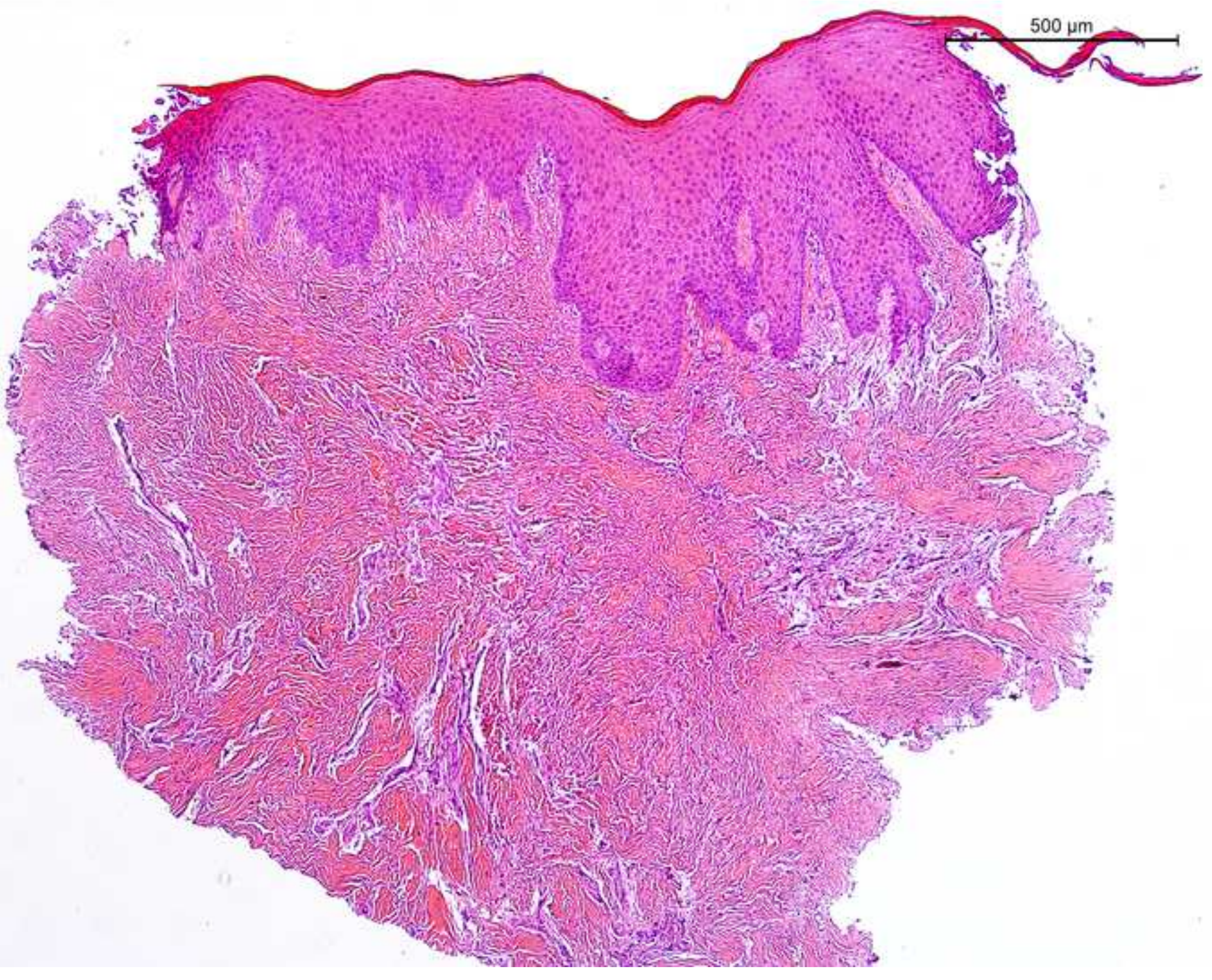

Figure 4A 


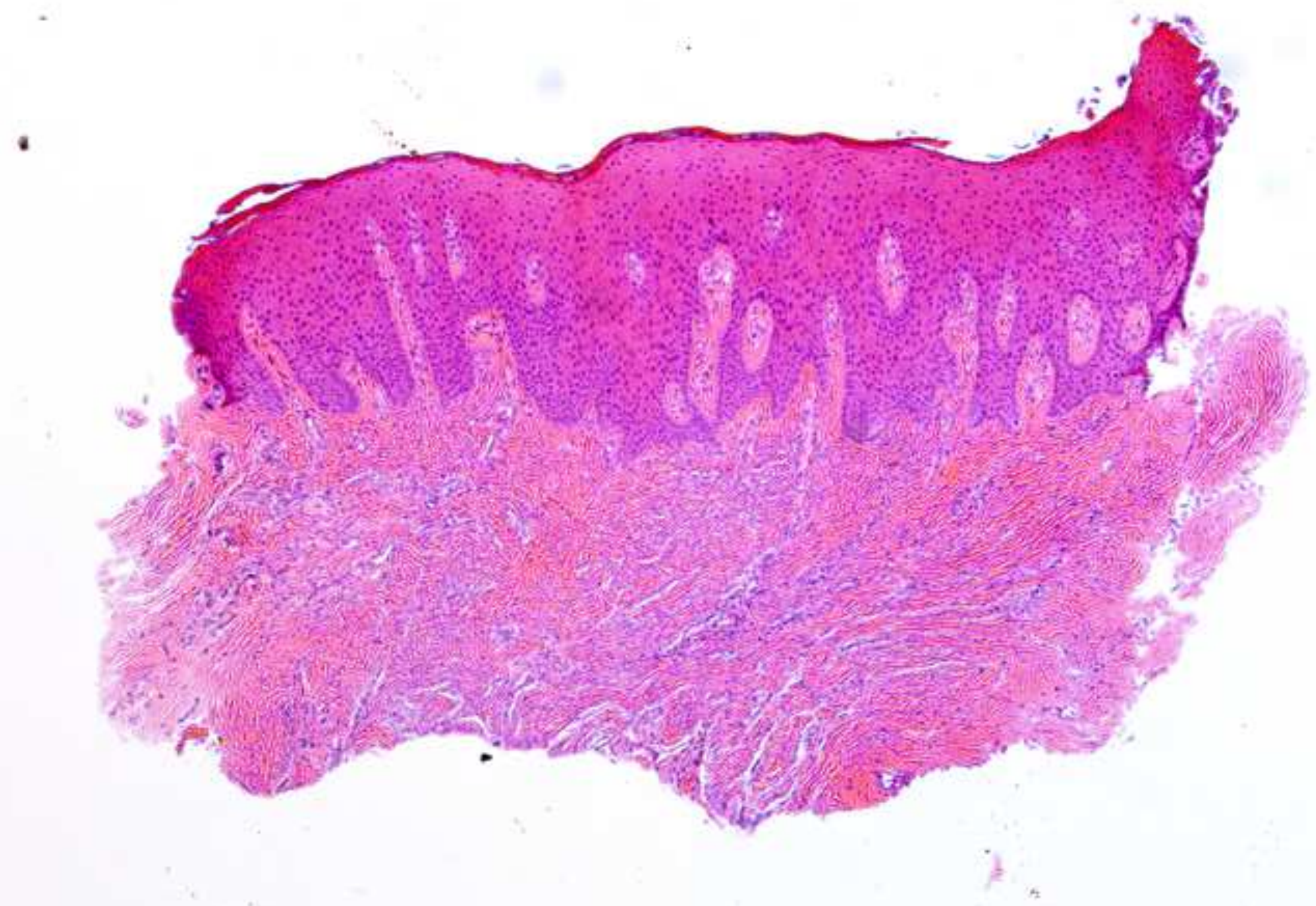

Figure 4B 


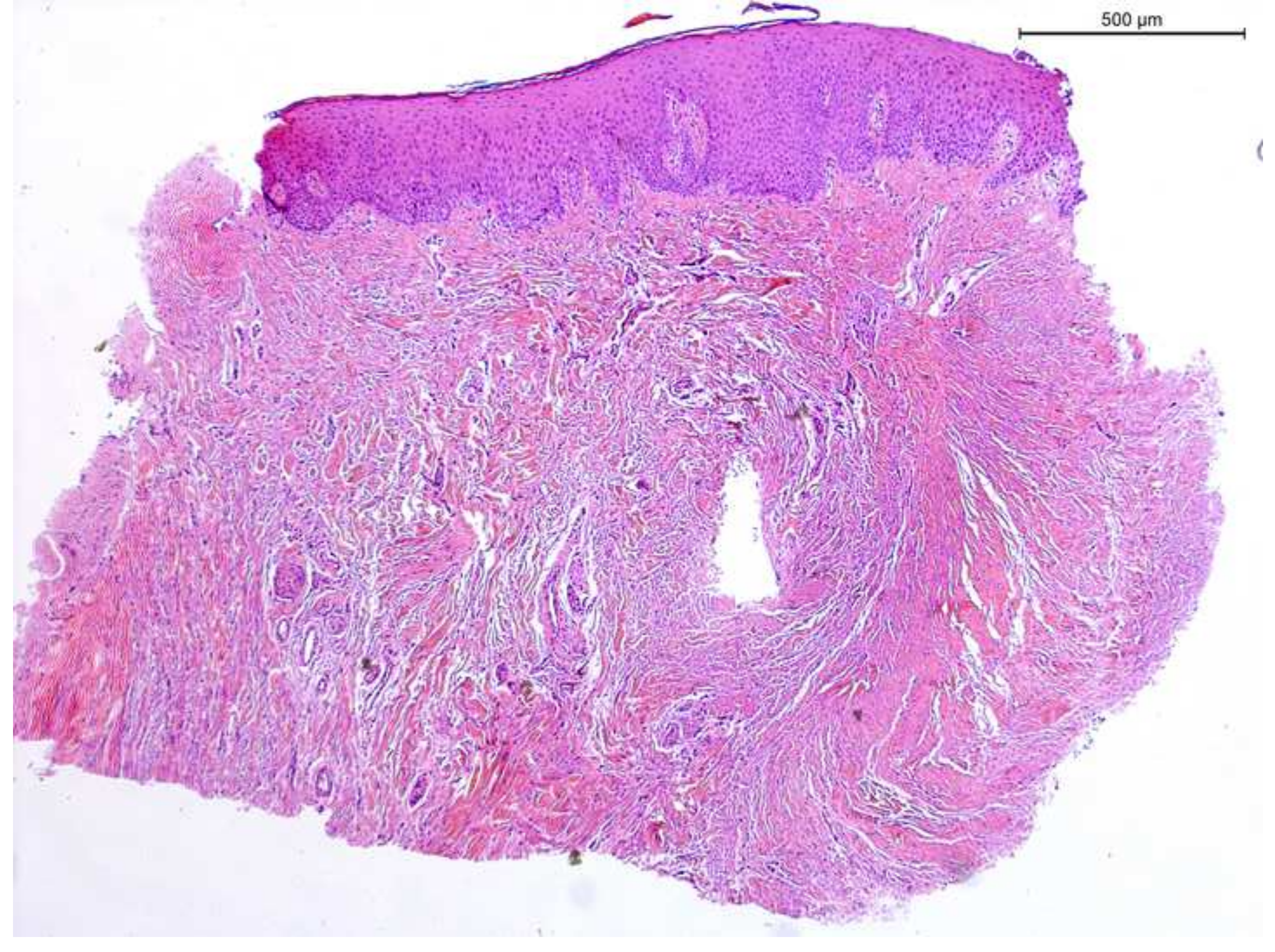

Figure 4C 


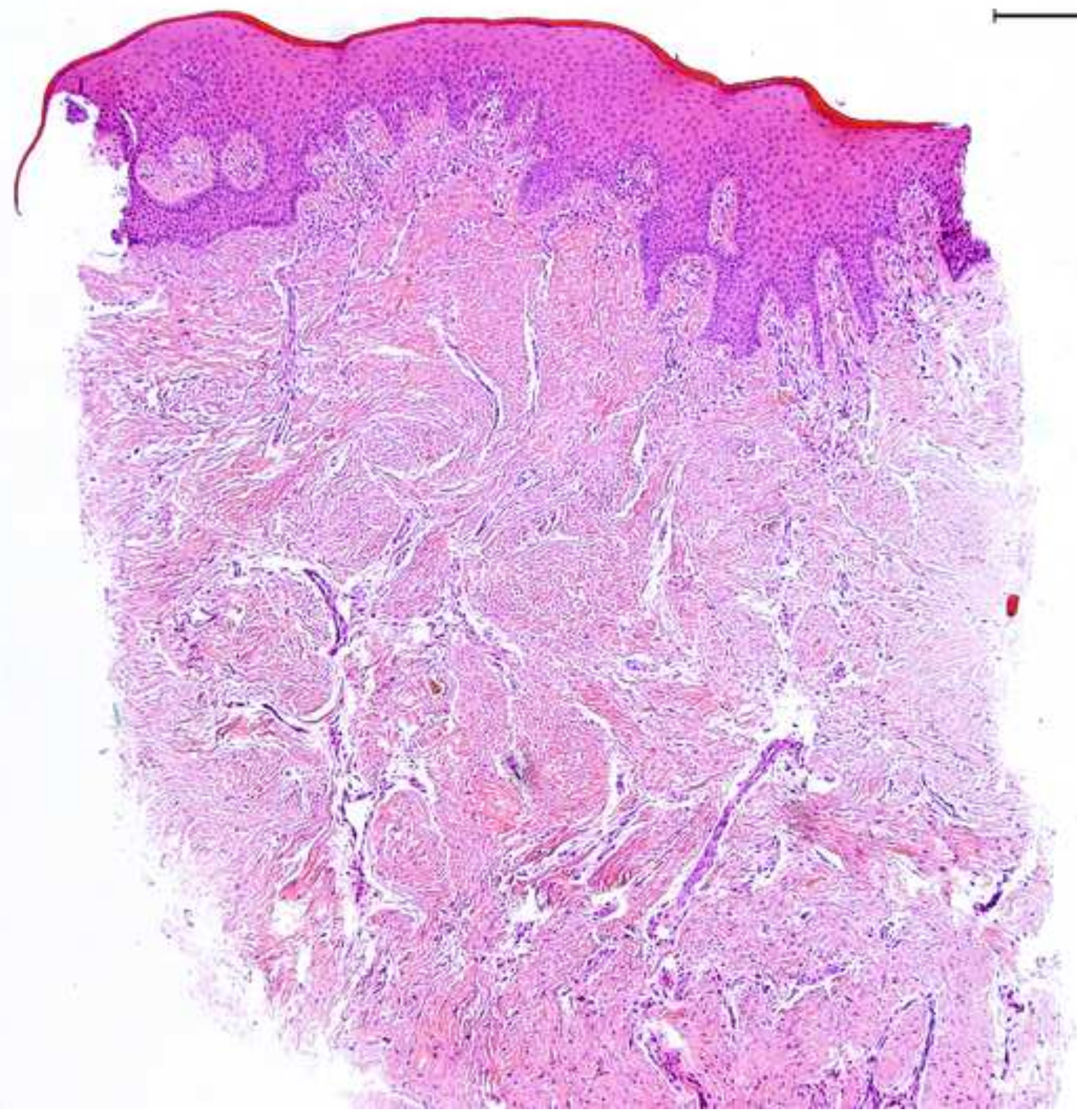

Figure 4D 
Table 1

\begin{tabular}{clllcccc}
\hline & $\begin{array}{l}\text { Bleeding } \\
\text { immediately } \\
\text { post-surgery }\end{array}$ & $\begin{array}{l}\text { Bleeding } \\
\text { 1-day post- } \\
\text { surgery }\end{array}$ & Swelling & $\begin{array}{c}\text { Pain } \\
\text { Absent } \\
0\end{array}$ & $\begin{array}{c}\text { Pain } \\
\text { Minimal } \\
1-3\end{array}$ & $\begin{array}{c}\text { Pain } \\
\text { Moderate } \\
4-6\end{array}$ & $\begin{array}{c}\text { Pain } \\
\text { Severe } \\
7-10\end{array}$ \\
\hline APF & $3(37 \%)$ & $1(12.5 \%)$ & $3(37 \%)$ & $2(25 \%)$ & $3(37 \%)$ & $3(37 \%)$ & 0 \\
XCM & $3(37 \%)$ & $1(12.5 \%)$ & $5(62.5 \%)$ & $2(25 \%)$ & $3(37 \%)$ & $2(25 \%)$ & $1(12.5 \%)$ \\
FGG & $4(50 \%)$ & $2(25 \%)$ & $5(62.5 \%)$ & $1(12.5 \%)$ & $4(50 \%)$ & $3(37 \%)$ & 0 \\
\hline
\end{tabular}


Table 2

\begin{tabular}{|c|c|c|c|c|c|c|}
\hline \multirow[t]{2}{*}{$\begin{array}{l}\text { Treatment } \\
\text { modality }\end{array}$} & \multirow[t]{2}{*}{$\begin{array}{l}\text { Observation } \\
\text { period }\end{array}$} & \multicolumn{5}{|c|}{$\begin{array}{c}\text { Change in width of keratinized } \\
\text { tissue }(\mathrm{mm})\end{array}$} \\
\hline & & $\Delta$ Mean & SD & Median & Q1 & Q3 \\
\hline APF & Pre- to Postoperative & 3.69 & 1.62 & 4 & 3.4 & 5 \\
\hline XCM & Pre- to Postoperative & 4.31 & 0.76 & 4.6 & 3.8 & 5 \\
\hline FGG & Pre- to Postoperative & 4.44 & 1.44 & 4.85 & 4.15 & 5.2 \\
\hline Control & Pre- to Postoperative & 0 & 0 & 0 & 0 & 0 \\
\hline APF & $\begin{array}{c}\text { Preoperative to } 30 \\
\text { days }\end{array}$ & 3.1 & 1.71 & 2.7 & 1.75 & 3.95 \\
\hline XCM & $\begin{array}{c}\text { Preoperative to } 30 \\
\text { days }\end{array}$ & 4.35 & 1.81 & 3.9 & 3.1 & 4.75 \\
\hline FGG & $\begin{array}{c}\text { Preoperative to } 30 \\
\text { days }\end{array}$ & 4.071 & 1.43 & 4.8 & 3.1 & 5.15 \\
\hline Control & $\begin{array}{c}\text { Preoperative to } 30 \\
\text { days }\end{array}$ & 0.16 & 0.29 & 0 & 0 & 0 \\
\hline APF & $\begin{array}{c}\text { Preoperative to } 90 \\
\text { days }\end{array}$ & 1.93 & 1.6 & 1.7 & 0.7 & 2.3 \\
\hline XCM & $\begin{array}{c}\text { Preoperative to } 90 \\
\text { days }\end{array}$ & 4.63 & 1.25 & 4.5 & 3.6 & 6 \\
\hline FGG & $\begin{array}{c}\text { Preoperative to } 90 \\
\text { days }\end{array}$ & 3.64 & 2.01 & 4.3 & 2.1 & 4.7 \\
\hline Control & $\begin{array}{c}\text { Preoperative to } 90 \\
\text { days }\end{array}$ & 0.13 & 0.312 & 0 & 0 & 0 \\
\hline
\end{tabular}

